\title{
SLON MAGNETIC SEPARATORS APPLIED IN THE ILMENITE PROCESSING INDUSTRY
}

\author{
XIONG DAHE* \\ Ganzhou Nonferrous Metallurgy Research Institute, 36 Qingnian Road, \\ Ganzhou 341000, Jiangxi Province, P.R. China
}

(Received 10 September 2004; Accepted 18 September 2004)

\begin{abstract}
SLon vertical ring pulsating high gradient magnetic separators possess the advantages of a large beneficial ratio, high processing efficiency, strong adaptability, high resistance of the magnetic matrix to clogging, and high equipment availability. In recent years, these separators have been successfully applied to the beneficiation of ilmenite ores at the Panzhihua Ilmenite concentrator, and several other ilmenite processing plants, promoting the rapid development of the ilmenite industry in China.
\end{abstract}

Keywords: SLon high-gradient magnetic separator; Ilmenite; Matrix

\section{INTRODUCTION}

The ilmenite deposit in Panzhihua region, Sichuan Province of China accounts for 35\% of the titanium resource in the world, and for approximately of $92 \%$ in China. Efficient utilization of the ilmenite resources is very important for development of the titanium industry.

Because a SLon vertical ring pulsating high gradient magnetic separator (SLon VP HGMS) possesses the advantages of high efficiency, a high beneficiation ratio, a high resistance of the matrix to clogging and high reliability $[1,2,3,4,5,6,7]$, they have been widely applied, in recent years, in the ilmenite processing industry in China.

\section{MINERALOGICAL FEATURES}

The Panzhihua deposit consists of vanadium, titanium and iron minerals and other gangue minerals. Magnetite is the major iron mineral and vanadium exists in magnetite. Ilmenite is the major titanium mineral. A typical elemental assay and mineralogical analysis of ilmenite-containing minerals are shown in Tables I and II, respectively.

*E-mail: xdh@slon.com.cn 
TABLE I Elemental assay of Panzhihua Ore

\begin{tabular}{lccccccccc}
\hline Element $(\%)$ & & & & & & & & \\
TFe & $\mathrm{FeO}$ & $\mathrm{Fe}_{2} \mathrm{O}_{3}$ & $\mathrm{TiO}_{2}$ & $\mathrm{~V}_{2} \mathrm{O}_{5}$ & $\mathrm{SiO}_{2}$ & $\mathrm{Al}_{2} \mathrm{O}_{3}$ & $\mathrm{CaO}$ & $\mathrm{MgO}$ & $\mathrm{Na}_{2} \mathrm{O}$ \\
27.10 & 18.51 & 18.46 & 6.51 & 0.27 & 26.64 & 9.95 & 3.90 & 9.15 & 0.51 \\
$\mathrm{~K}_{2} \mathrm{O}$ & $\mathrm{S}$ & $\mathrm{P}$ & $\mathrm{MnO}$ & $\mathrm{Cu}$ & $\mathrm{Co}$ & $\mathrm{Ni}$ & $\mathrm{Cr}_{2} \mathrm{O}_{3}$ & Roasting lost \\
0.28 & 0.35 & 0.038 & 0.32 & 0.027 & 0.020 & 0.024 & 0.025 & 4.80 \\
\hline
\end{tabular}

TABLE II Mineralogical analysis of Panzhihua Ore

\begin{tabular}{lccccccc}
\hline Mineral & Magnetite & Hematite & Ilmenite & Pyrite & Olivine & Titaniferous augite & Plagioclase \\
Mass (\%) & 30.6 & 3.5 & 6.1 & 0.7 & 16.2 & 13.1 & 15.8 \\
& Hornblende & Mica & Chlorite & Cyphoite & Kaolin & Spinel & Others \\
& 2.3 & 0.2 & 4.2 & 3.0 & 3.6 & 0.5 & 0.2 \\
\hline
\end{tabular}

TABLE III Elemental assay of the tails of LIMS

\begin{tabular}{lcccccccc}
\hline Element $(\%)$ & & & & & & & & \\
$\mathrm{TFe}$ & $\mathrm{FeO}$ & $\mathrm{Fe}_{2} \mathrm{O}_{3}$ & $\mathrm{TiO}_{2}$ & $\mathrm{~V}_{2} \mathrm{O}_{5}$ & $\mathrm{SiO}_{2}$ & $\mathrm{Al}_{2} \mathrm{O}_{3}$ & $\mathrm{CaO}$ & $\mathrm{MgO}$ \\
13.40 & 10.56 & 7.37 & 9.51 & 0.072 & 35.76 & 11.67 & 11.22 & 9.26 \\
$\mathrm{Na}_{2} \mathrm{O}$ & $\mathrm{K}_{2} \mathrm{O}$ & $\mathrm{S}$ & $\mathrm{P}$ & $\mathrm{Cu}$ & $\mathrm{Co}$ & $\mathrm{Ni}$ & $\mathrm{Cr}_{2} \mathrm{O}_{3}$ & \\
0.68 & 0.85 & 0.564 & 0.021 & 0.015 & 0.019 & 0.012 & 0.008 \\
\hline
\end{tabular}

TABLE IV Typical mineral properties in the tailings of LIMS

\begin{tabular}{|c|c|c|c|c|c|c|}
\hline Mineral & Molecule & $\begin{array}{l}\text { Mass } \\
(\%)\end{array}$ & $\begin{array}{c}\text { Grade } \\
\left(\mathrm{TiO}_{2} \%\right)\end{array}$ & $\begin{array}{l}\text { Specific } \\
\text { density } \\
\left(\mathrm{g} / \mathrm{cm}^{3}\right)\end{array}$ & $\begin{array}{c}\text { Magnetic } \\
\text { susceptibility } \\
\left(\times 10^{-6} \mathrm{~cm}^{3} / \mathrm{g}\right)\end{array}$ & $\begin{array}{c}\text { Specific } \\
\text { Resistance } \\
(\Omega \mathrm{cm})\end{array}$ \\
\hline $\begin{array}{l}\text { Vanadium-titanium } \\
\text { magnetite }\end{array}$ & $(\mathrm{V}, \mathrm{Ti}, \mathrm{Fe})_{3} \mathrm{O}_{4}$ & $2-5$ & 13.4 & $4.6-4.8$ & $>1000$ & $1.38 \times 10^{6}$ \\
\hline Ilmenite & $\mathrm{FeTiO}_{3}$ & $15.3-17.5$ & 51.89 & $4.6-4.7$ & 240 & $1.75 \times 10^{5}$ \\
\hline Titaniferous Augite & $\mathrm{Ca}(\mathrm{Mg}, \mathrm{Fe}, \mathrm{Ti})\left[(\mathrm{Si}, \mathrm{Al})_{2} \mathrm{O}_{6}\right]$ & $46-46.5$ & 1.85 & $3.2-3.3$ & 100 & $3.13 \times 10^{13}$ \\
\hline Pyrite & $\mathrm{FeS}_{2}$ & $2-2.5$ & & $4.4-4.9$ & 4100 & $1.25 \times 10^{4}$ \\
\hline Plagioclase & $(100-n) \mathrm{Na}\left[\mathrm{AlSi}_{3} \mathrm{O}_{8}\right] \cdot n \mathrm{Ca}\left[\mathrm{Al}_{2} \mathrm{Si}_{2} \mathrm{O}_{8}\right]$ & $31-34$ & 0.097 & 2.7 & 14 & $>10^{14}$ \\
\hline
\end{tabular}

All of the mineral processing plants in the Panzhihua region recover magnetite with low-intensity magnetic separation (LIMS), while the tailings which contain about $10 \% \mathrm{TiO}_{2}$, serve as the feed to various ilmenite processing flowsheet. The typical elemental assay and mineral properties in the tailings of LIMS are shown in Tables III and IV.

\section{SLON VP HGMS APPLIED TO THE RECOVERY OF FINE ILMENITE}

The Panzhihua Ilmenite Processing Plant is the biggest producer of ilmenite concentrate in China. The iron processing plant recovers magnetite and vanadium before the ilmenite processing plant. The tailings from the iron processing plant represent the feed into the ilmenite processing plant. 
The previous flowsheet of the ilmenite processing plant was based on classification into $+0.1 \mathrm{~mm}$ (coarse), $-0.045+0.1 \mathrm{~mm}$ (middle) and $-0.045 \mathrm{~mm}$ (fine) fractions. The coarse and middle particle fractions were treated with spirals and electrical separators. The fine fraction was discarded as the final tailings for the lack of efficient beneficiation technology. The overall recovery of ilmenite had been only $17-20 \%$ of the feed to the ilmenite processing plant.

In recent years, the mass of the fine fraction has reached about $50 \%$ as the iron processing plant grinding became finer and finer for higher iron concentrate grade. The $\mathrm{TiO}_{2}$ grade of the fine fraction is almost the same as that of the feed to the ilmenite plant. The recovery of ilmenite from the fine particle fraction is getting more and more important in order to increase the overall recovery of the ilmenite plant.

From 1997 to 2004, the Panzhihua Ilmenite Processing Plant built two circuits for the recovery of $-0.045 \mathrm{~mm}$ ilmenite using the SLon VP HGMS-Flotation flowsheet. Twelve SLon-1500 VP HGMS are applied as roughers, followed by flotation for cleaning as shown in Figs. 1 and 2.

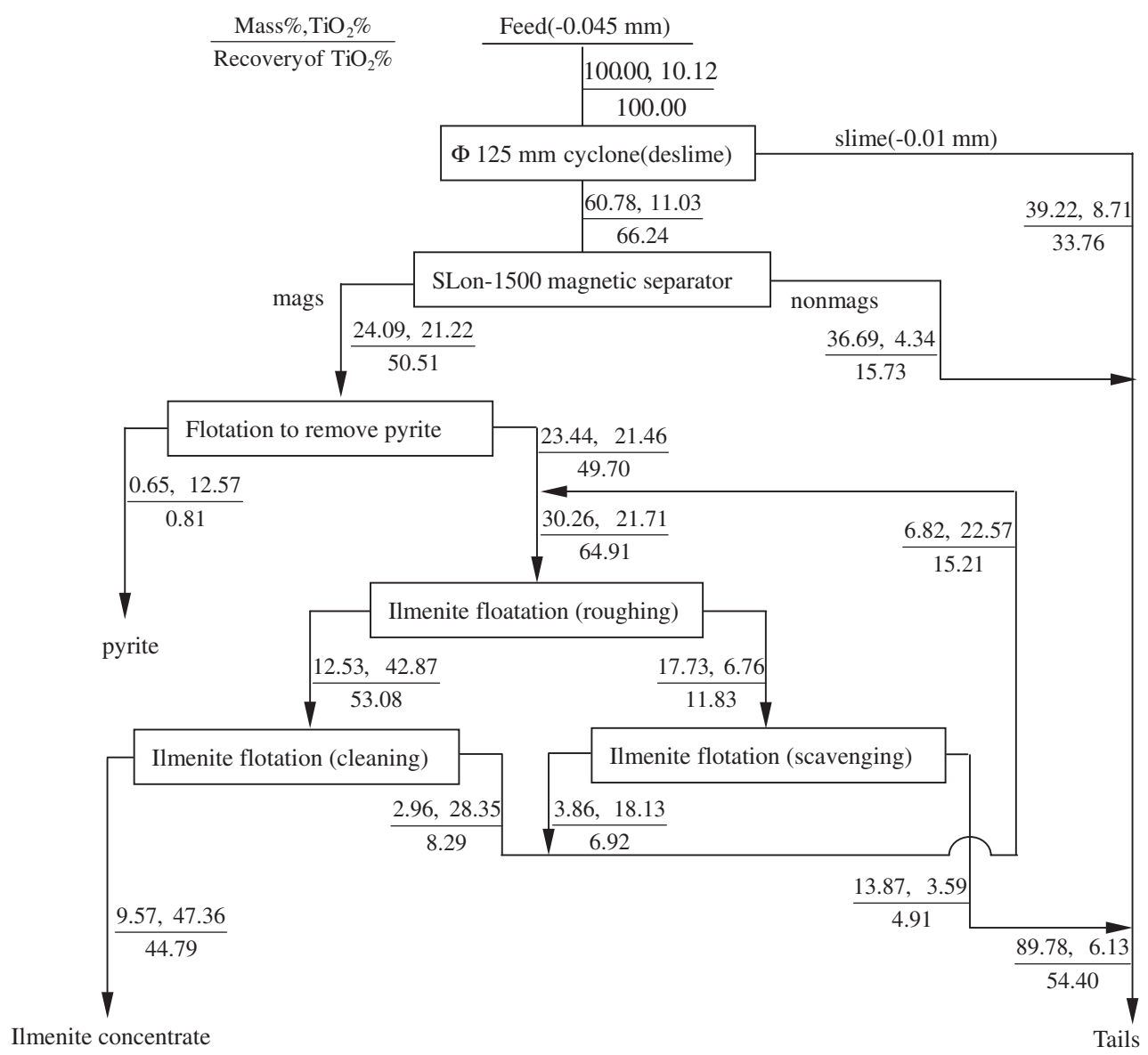

FIGURE 1 Twelve SLon-1500 VP HGMS machines are applied to the recovery of $-0.045 \mathrm{~mm}$ ilmenite in the Panzhihua Ilmenite Processing Plant. 


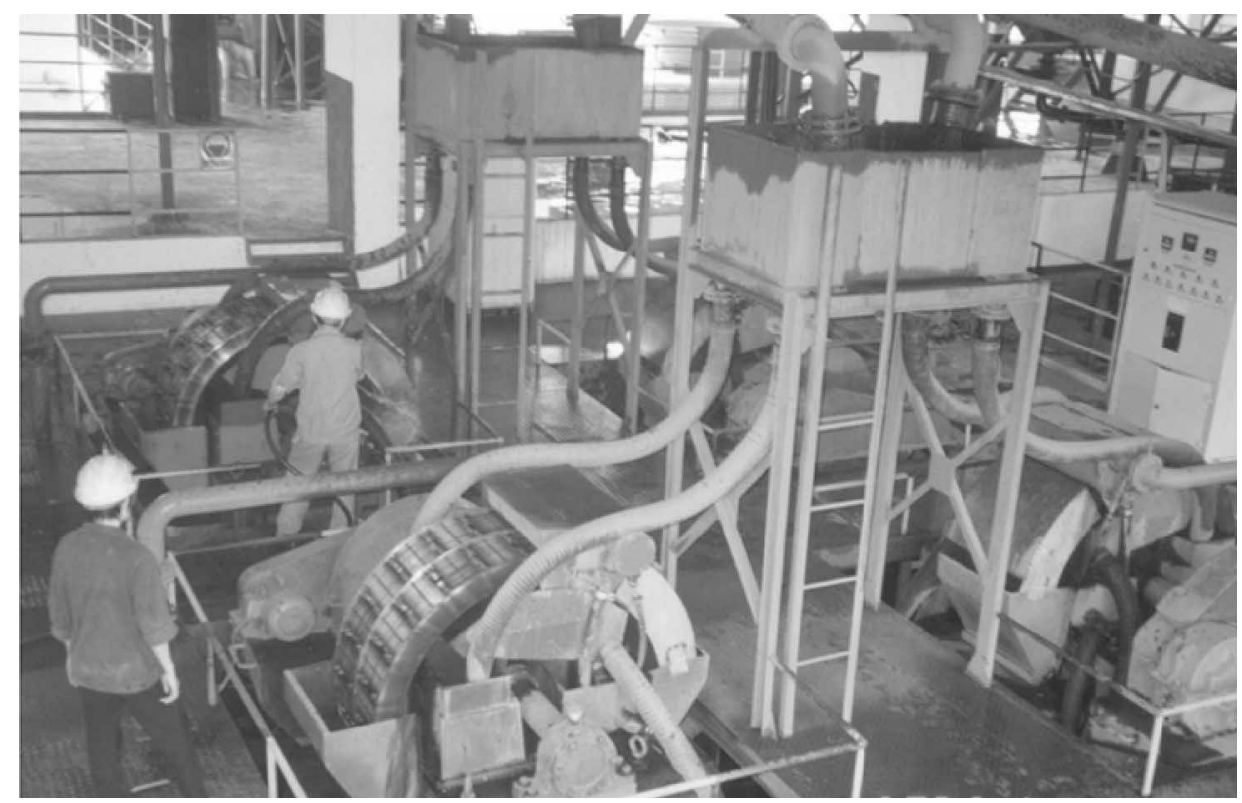

FIGURE 2 A photograph of SLon-1500 VP HGMS in the Panzhihua Ilmenite Processing Plant.

The SLon VP HGMS operation is very important. It discards most of the gangue and slimes before flotation. Only a small mass portion containing about $21.22 \% \mathrm{TiO}_{2}$ enters flotation. It creates a very good condition for flotation, which guarantees that the flotation operation can get good results at low cost. The total results of the flowsheet are: feed grade $12.12 \% \mathrm{TiO}_{2}$, ilmenite concentrate grade $47-48 \% \mathrm{TiO}_{2}$, recovery $44.79 \% \mathrm{TiO}_{2}$.

Now The Panzhihua Ilmenite Processing Plant produces 150000 tonnes of $-0.045 \mathrm{~mm}$ ilmenite concentrate with average $47.5 \% \mathrm{TiO}_{2}$ each year. $\mathrm{The}^{\mathrm{TiO}_{2}}$ overall recovery of the plant was increased from $17-20 \%$ to about $35 \%$.

\section{APPLICATION OF SLON VP HGMS FOR THE RECOVERY OF ILMENITE FROM THE PANZHIHUA TAILINGS}

The Panzhihua Iron and Steel Company treats 10 million tones of iron ore annually. Approximately 5.7 million tonnes of tailings from the low-intensity magnetic separation circuit, containing about $9.5 \% \mathrm{TiO}_{2}$ serve as the feed to the Panzhihua Ilmenite Processing Plant as mentioned above. After a portion of ilmenite is recovered into the magnetic concentrate, the tailings of the plant still contain about $7 \% \mathrm{TiO}_{2}$, in about 5.4 million tonnes that are discharged and pumped to the tailings dump.

In the past few years, a mineral processing plant has been built at the middle of the pumping pipeline to recover the remaining iron and ilmenite minerals from the discarded tailings. The flowsheet is shown in Fig. 3. Low intensity magnetic separators recover the remaining magnetite. Two SLon-1500 VP HGMS are applied as the roughing stage and one SLon-1500 VP HGMS is used as the cleaning stage to recover 


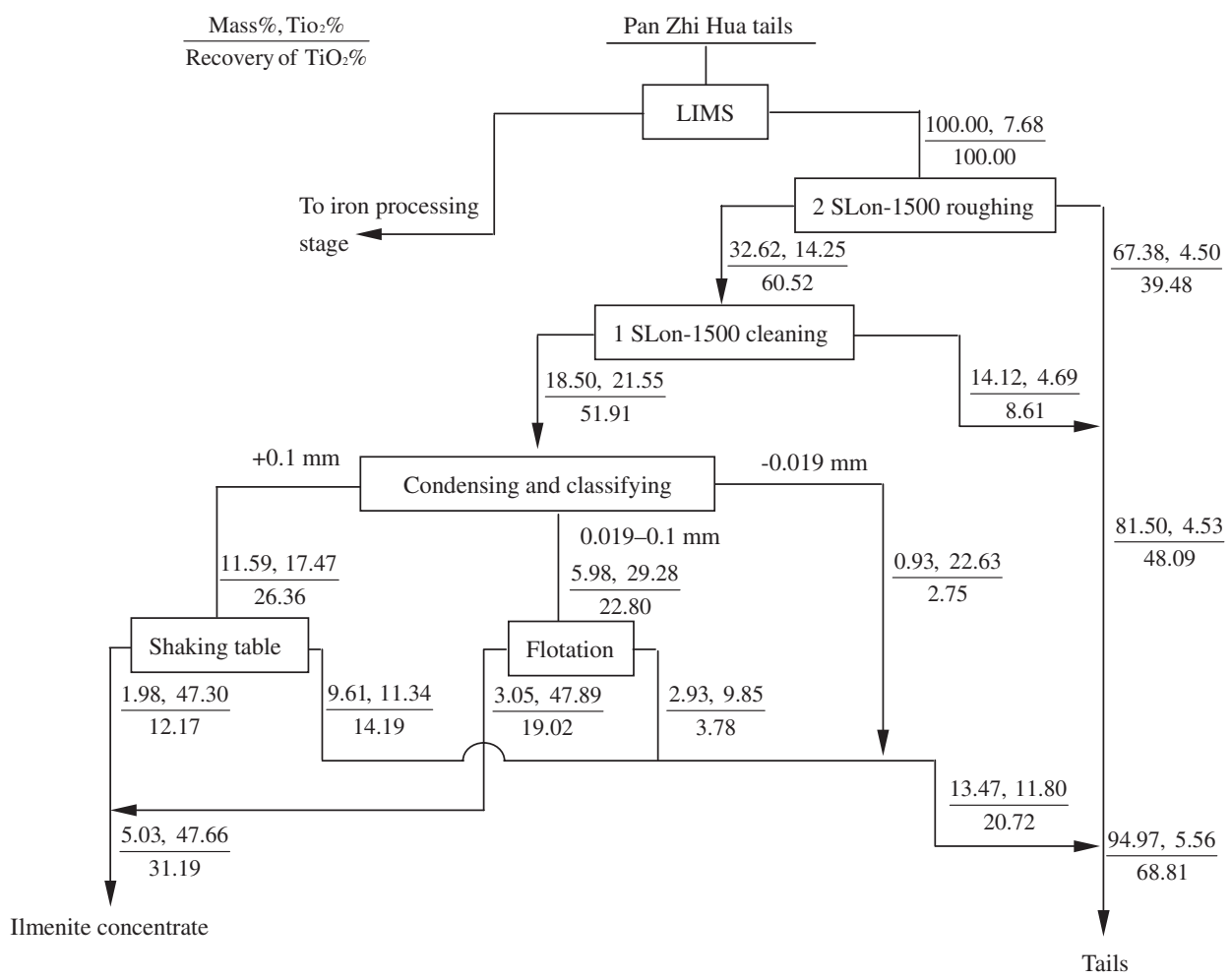

FIGURE 3 Three SLon-1500 VP HGMS units are used to recover ilmenite from the tailings.

ilmenite. As the Panzhihua tailings are enormous, the feed into each SLon-1500 at the roughing stage is about $45 \mathrm{t} / \mathrm{h}$ (nominally 20 to $30 \mathrm{t} / \mathrm{h}$ ), so that as much ilmenite as possible is recovered. The magnetic fraction of the cleaning SLon-1500 containing $21.55 \% \mathrm{TiO}_{2}$ are condensed and classified into $+0.1 \mathrm{~mm}$ (coarse), $-0.1+0.019 \mathrm{~mm}$ (fine) and $-0.019 \mathrm{~mm}$ (slime) fractions. The coarse fraction is cleaned further by shaking tables and the fine fraction is cleaned further by flotation. The slime is discharged directly as the final tailings. The advantages of this flowsheet are that three SLon-1500 separators discharge $81.5 \%$ of the mass fraction to the final tailings at very low cost. Only $18.50 \%$ mass fraction enters the further cleaning stages. The results of the total flowsheet are: feed grade $7.68 \% \mathrm{TiO}_{2}$, ilmenite concentrate grade $47.66 \% \mathrm{TiO}_{2}, \mathrm{TiO}_{2}$ recovery $31.19 \%$. This flowsheet recovers 30000 tonnes of the ilmenite concentrate annually, at good quality, and about 50000 tonnes of the iron concentrate is also recovered each year.

\section{APPLICATION OF THE SLON VP HGMS TO THE RECOVERY OF ILMENITE IN THE TAIHE IRON MINE}

The Taihe Iron Mine is located in Xichang of the Si Chuan Province, close to the Panzhihua Region. Its ore is similar to the Panzhihua ore. A low-intensity magnetic 
separation (LIMS) circuit was installed to recover magnetite before 1994. In 1994 to 1995, an ilmenite processing circuit was introduced to produce ilmenite concentrate from the tailings from the LIMS circuit. At first spirals and shaking tables were used as roughers and flotation was used as cleaner, however spirals and shaking tables were not able to recover fine ilmenite particles. Their roughing concentrate contained only coarse particles, and the flotation cleaning stage was not able to recover coarse ilmenite particles. Therefore, high losses of $\mathrm{TiO}_{2}$ from the coarse and fine fractions were incurred. The $\mathrm{TiO}_{2}$ recovery was, therefore, very low, only about $10 \% \mathrm{TiO}_{2}$ from the LIMS tailings. The ilmenite concentrate production was only 2000 tonnes per annum.

In 2000, three SLon-1500 VP HGMS units were installed at the Taihe Iron Mine to recover ilmenite. Two SLon-1500 separators replaced the previously used spirals and one SLon-1500 separator replaced the previously used shaking tables. These three SLon-1500 separators are incorporated, together with the flotation circuit, into a magnetic-flotation flowsheet as shown in Fig. 4.

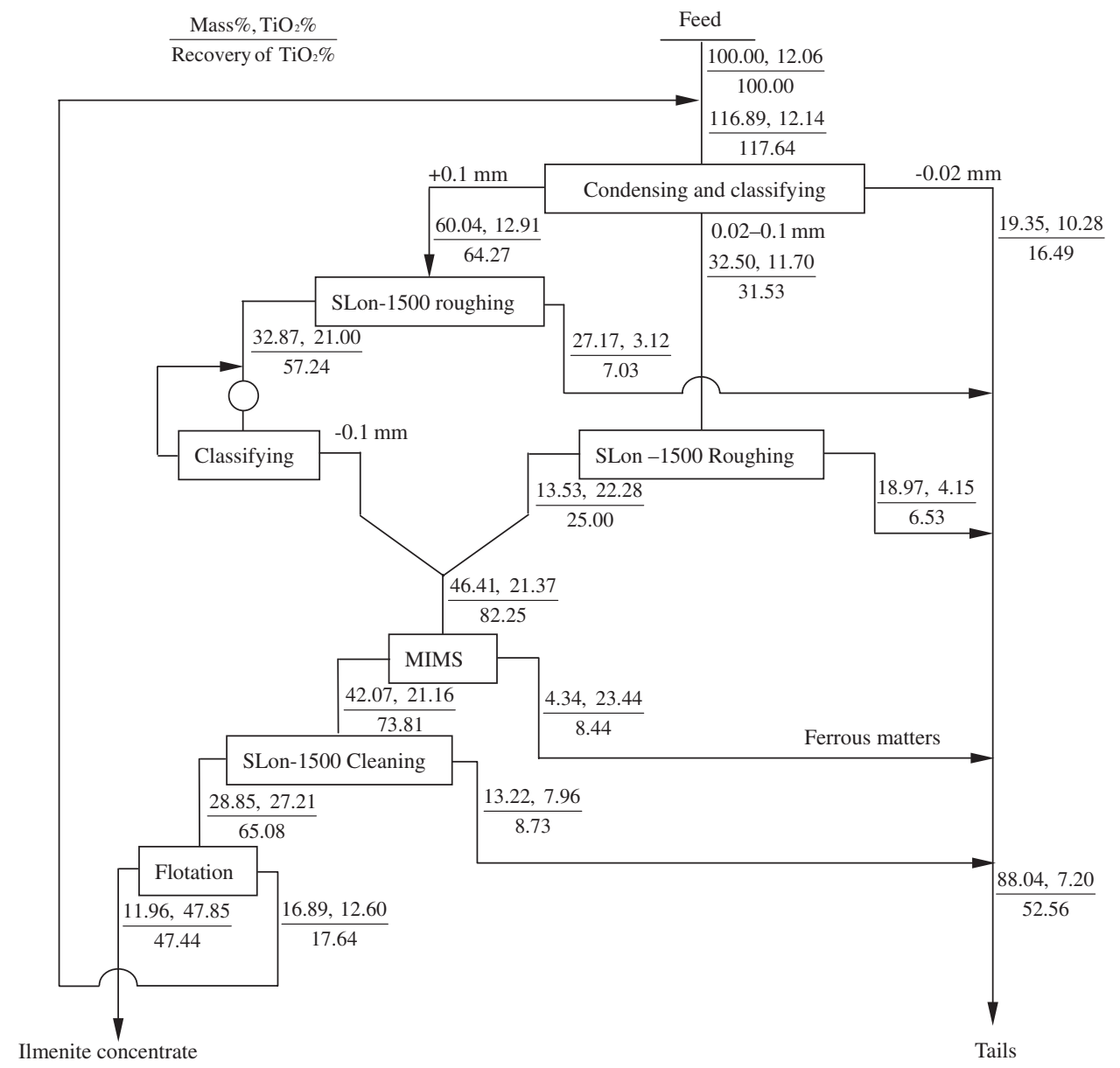

FIGURE 4 Three SLon-1500 high-gradient magnetic separators are applied at the Taihe ilmenite processing flowsheet. 
In the first stage, the feed (the tailings from LIMS) is thickened and classified into $+0.1 \mathrm{~mm}$ (coarse), $-0.02+0.1 \mathrm{~mm}$ (fine) and $-0.02 \mathrm{~mm}$ (slime) fractions. The coarse and the fine fractions are roughed separately by two SLon-1500 separators. The coarse magnetics from the SLon machine are milled to $-0.1 \mathrm{~mm}$, and mixed with the fine magnetics from the SLon-1500 unit. A medium-intensity magnetic separator (MIMS) of the drum type is used to remove the remaining magnetite and other ferrous materials. The non-magnetics from the MIMS machine are cleaned by a SLon-1500 separator, the magnetics of which are fed into the flotation stage for further cleaning.

The advantages of this flowsheet are as follows:

(1) The coarse and the fine fractions are treated separately by SLon VP HGMS, so that different magnetic parameters can be chosen for optimal results.

(2) The grade of the feed into the flotation circuit is relatively high, about $27.21 \%$ $\mathrm{TiO}_{2}$, which saves flotation reagents and reduces the production costs.

(3) The flotation tailings containing about $12.60 \% \mathrm{TiO}_{2}$ are returned to the feed of the flowsheet which helps to increase $\mathrm{TiO}_{2}$ recovery.

This flowsheet recovers effectively coarse and fine ilmenite fractions. It guarantees that the grade of the ilmenite concentrate is greater than $47 \% \mathrm{TiO}_{2}$ and the overall recovery of $\mathrm{TiO}_{2}$ is increased to approximately $47 \%$. Presently the production of the ilmenite concentrate at the Taihe Mine reaches 40000 tonnes per annum, compared to the previous production of 2000 tonnes per annum. In 2003 to 2004, this mine ordered additional three SLon-1750 VP HGMS machines to scale-up the ilmenite processing flowsheet. The work is expected to be completed in 2005 .

\section{CONCLUSION}

(1) SLon vertical ring pulsating high-gradient magnetic separators possess the advantages of large beneficiation ratio, high mineral processing efficiency, high resistance of the matrix to clogging, high throughput, high equipment reliability and availability. In recent years, these separators have been successfully applied in eight Chinese ilmenite processing plants. Three typical examples of ilmenite processing flowsheet are described in this article.

(2) Twelve SLon-1500 VP HGMS units are applied at Panzhihua Ilmenite Processing Plant to recover $-0.045 \mathrm{~mm}$ ilmenite. These separators are used to beneficiate the feed containing $10.12 \% \mathrm{TiO}_{2}$ to $21.22 \% \mathrm{TiO}_{2}$, at low cost. The mass of SLon magnetic concentrate is only $24.09 \%$, which is very favorable for the following flotation cleaning stage. The overall results of the magnetic-flotation flowsheet are: feed grade $10.12 \% \mathrm{TiO}_{2}$, ilmenite concentrate grade $47.36 \% \mathrm{TiO}_{2}$, recovery $44.79 \%$ $\mathrm{TiO}_{2}$. Each year 150000 tonnes of the ilmenite concentrates of good quality are produced by this flowsheet.

(3) Three SLon-1500 VP HGMS machines are applied to recover ilmenite from the Panzhihua tailings; two of them are used as roughers and the other is used as a cleaner. These machines enrich the feed, with wide size distribution, from $7.68 \% \mathrm{TiO}_{2}$ to $21.55 \% \mathrm{TiO}_{2}$, The SLon magnetics are then classified into $+0.1 \mathrm{~mm}$ (coarse), $-0.019+0.1 \mathrm{~mm}$ (fine), $-0.019 \mathrm{~mm}$ (slime) fractions. The coarse fraction is further cleaned by shaking tables and the fine fraction is further 
cleaned by flotation. The overall results of this magnetic - gravity-flotation flowsheet are: feed grade $7.68 \% \mathrm{TiO}_{2}$, ilmenite concentrate grade $47.66 \% \mathrm{TiO}_{2}$, recovery $31.19 \% \mathrm{TiO}_{2}$. Annually, 30000 tonnes of good quality ilmenite concentrate are produced.

(4) Three SLon-1500 VP HGMS units are applied in the Taihe ilmenite processing flowsheet. The feature of this flowsheet is that the feed is first classified into $+0.1 \mathrm{~mm}$ (coarse), $+0.02-0.1 \mathrm{~mm}$ (fine), $-0.02 \mathrm{~mm}$ (slime) fractions. The coarse and the fine fractions are then roughed by the SLon-1500 separators separately for optimized results. The coarse magnetics of a SLon- 1500 separator is ground to $-0.1 \mathrm{~mm}$, mixed with the fine magnetics from the other SLon-1500 separator, and then cleaned by the third SLon-1500 machine, the magnetics of which are further cleaned by flotation. The overall results of this magnetic - magnetic-flotation flowsheet are: feed grade $12.06 \% \mathrm{TiO}_{2}$, ilmenite concentrate grade $47.85 \% \mathrm{TiO}_{2}$, recovery $47.44 \% \mathrm{TiO}_{2}$. Annually 40000 tonnes of the ilmenite concentrates of good quality are produced.

(5) In all of the ilmenite processing flowsheet mentioned in this article, SLon VP HGMS machines are used as roughers or first cleaners. The separators successfully remove most of the gangue at low cost and leave a small mass portion for the final cleaning stage. SLon VP HGMS machines also discard all of the $-10 \mu \mathrm{m}$ slimes which otherwise would be harmful to flotation. As the ilmenite flotation reagents are expensive, SLon VP HGMS units greatly reduce the total cost of the ilmenite concentrate production.

(6) The applications of SLon VP HGMS separators successfully solved the difficult problem of beneficiation of the $-0.045 \mathrm{~mm}$ ilmenite fraction, greatly increased the ilmenite recovery and greatly reduced the production cost. The successful applications of SLon VP HGMS separators in the ilmenite processing industry significantly promoted the rapid development of Chinese titanium industry.

\section{References}

[1] Xiong Dahe, New development of the SLon vertical ring and pulsation HGMS separator. Magn. Electr. Sep., 5 (1994), 211-222.

[2] Xiong Dahe, Development and commercial test of SLon-2000 vertical ring pulsating high gradient magnetic separator. Magn. Electr. Sep., 8 (1997), 89-100.

[3] Xiong Dahe, Development and applications of SLon vertical ring pulsating high gradient magnetic separators, In: Proc. XX IMPC, Aachen, Germany, 21-26 September 1997, pp. 621-630.

[4] Xiong Dahe, Shuyi Liu and Jin Chen, New technology of pulsating high gradient magnetic separation. Int. J. Miner. Process., 54 (1998), 111-127.

[5] Xiong Dahe, Research and commercialisation of treatment of fine ilmenite with SLon magnetic separators. Magn. Electr. Sep., 10 (2000), 121-130.

[6] Xiong Dahe, A large scale application of SLon magnetic separator in Meishan Iron Ore Mine. Magn. Electr. Sep., 11 (2002), 1-8.

[7] Xiong Dahe, SLon magnetic separator applied to upgrading the iron concentrate. Phys. Sep. Sci. Engn., 12 (2003), 63-69. 